\title{
Methods of deconditioning persisting avoidance: Amphetamine and amobarbital as adjuncts to response prevention
}

\author{
DANIEL CHRISTY and LARRY REID \\ Bradley University, Peoria, Illinois 61606
}

\begin{abstract}
Rats were trained to avoid footshock in an automated one-way avoidance box by climbing to a retractable ledge. After avoidance was well established ( 50 trials on 3 consecutive days), footshock was terminated. Groups then received response prevention (a forced stay on the grid by prolonged ledge retraction) under the influence of a placebo, one of two doses of amphetamine, or one of two doses of amobarbital. One group received no treatment. Three days after treatment procedures, subjects were tested for persistance of responding without further footshock. Response prevention by itself attenuated persisting responding compared to no treatment, and the only drug that further attenuated persisting responding was the low dose of amphetamine.
\end{abstract}

Baum (1970) has developed a paradigm for testing ways to reduce avoidance that persists beyond the termination of aversiveness. The paradigm involves an experimental space with a grid floor and a narrow retractable ledge extending through one wall. Rats can escape or avoid footshock by climbing to the ledge. After a rat has stayed briefly on the ledge, the ledge retracts from the box returning the rat to the grid. The ledge then returns to begin a new trial. Within a few trials, rats are consistantly avoiding footshock by ledge climbing before the advent of footshock. If the number of avoidance trials are numerous and if the footshock is intense, avoidance persists extensively beyond the termination of the possibility for footshock (Voss, Mejta, \& Reid, 1974).

To compare treatments for their effectiveness in reducing persisting avoidance, Baum (1970) has interposed a variety of treatments between termination of footshock and tests for perseveration of avoidance. Knowledge of which treatments efficiently reduce persisting avoidance is thought to be germaine to the development of psychotherapies for remediation of irrational hyperanxieties. The procedure of response prevention (RP) is among those treatments that have been tested. RP is typically arranged by leaving the ledge retracted, thereby preventing further ledge climbing and forcing the rat to confront the once dangerous grid. Moderately long and extended RP reduces persisting avoidance (Baum, 1970). A number of procedures (Baum, 1970) have been imposed during RP and tested for their effectiveness including drug administration (e.g., Baum, 1973; Kamano, 1972).

When rats are in RP and under the influence of drugs

This research was supported by Bradley University's Board for Research which administers National Science Foundation Grant GU 3320 and by HEW, National Institute of Drug Abuse Grant DA 01049-01. classed as tranquilizers or relaxants, their persisting avoidance is either enhanced or not different than rats given similar treatments without the drugs (Cooper, Coon, Mejta, \& Reid, 1974; Kamano, 1972). When amphetamine was tested in low doses (Cooper et al., 1974), it was found that RP under its influence led to a marked reduction in persisting avoidance. Because these results are divergent from certain expectations, this study again tested amphetamine's effects as well as the effects of amobarbital.

\section{METHOD}

\section{Subjects and Apparatus}

Forty-six adult (about $300 \mathrm{~g}$ ) male Sprague-Dawley rats, housed in individual cages with food and water always available, served as subjects.

The automated apparatus was similar to the one described in detail by Baum (1965). It was a clear plastic box $(30 \times 30 \times 39 \mathrm{~cm})$ with an electrifiable grid floor attached to a Grason-Stadler shock source and scrambler. The retractable ledge projected $7 \mathrm{~cm}$ into one side of the box $14 \mathrm{~cm}$ above the grid.

\section{Procedure}

Subjects received identical training. Without habituation to the apparatus, the subject was placed on the grid. Ten seconds later the grid was electrified, and the subject was shocked (1.3 mA) until it escaped to the ledge. Thirty seconds after ledge attainment, the ledge retracted, thereby forcing the subject to the grid. As the ledge returned, a new trial began. If the subject climbed to the ledge prior to the elapse of $10 \mathrm{sec}$, it avoided shock. All subjects received 150 trials, 50 trials on each of 3 consecutive days.

After 150th trial, each subject (with exception of subjects of no treatment) was given an intraperiotoneal injection of either d-amphetamine sulfate $(2 \mathrm{mg} / \mathrm{Kg}$ or $10 \mathrm{mg} / \mathrm{Kg})$, amobarbital $(10 \mathrm{mg} / \mathrm{Kg}$ or $20 \mathrm{mg} / \mathrm{Kg}$ ) or the water carrier of the other two drugs $(1 \mathrm{ml} / \mathrm{Kg})$. Subjects of no treatment were immediately returned to thier home cage and subjects of injections were returned as soon as they received their injection.

After $30 \mathrm{~min}$ in the home cage, a time sufficient for drugs to become effective, all injected subjects were returned to the 
Table 1

Treatments and Outcomes

\begin{tabular}{|c|c|c|c|c|c|c|}
\hline \multirow{3}{*}{$\begin{array}{l}\text { RP } \\
(\min ) \\
\text { Drug }\end{array}$} & \multicolumn{6}{|c|}{ Treatments } \\
\hline & 0 & 10 & 10 & 10 & 10 & 10 \\
\hline & None & Placebo & $\begin{array}{c}\text { Amphe } \\
2 \\
\mathrm{mg} / \mathrm{Kg}\end{array}$ & $\begin{array}{c}\text { amine } \\
10 \\
\mathrm{mg} / \mathrm{Kg}\end{array}$ & $\begin{array}{c}10^{\mathrm{Am}} \\
\mathrm{mg} / \mathrm{Kg}\end{array}$ & $\begin{array}{l}\mathrm{tal} \\
20 \\
\mathrm{mg} / \mathrm{Kg}\end{array}$ \\
\hline \multicolumn{7}{|c|}{ Trials to Criterion } \\
\hline $\begin{array}{l}\text { Raw } \\
\text { Data }\end{array}$ & $\begin{array}{l}162 \\
208 \\
219 \\
289 \\
401 \\
444 \\
536\end{array}$ & $\begin{array}{c}1 \\
3 \\
3 \\
36 \\
96 \\
102 \\
110 \\
128 \\
145 \\
173 \\
700+\end{array}$ & $\begin{array}{r}0 \\
3 \\
19 \\
22 \\
23 \\
56 \\
95\end{array}$ & $\begin{array}{c}10 \\
11 \\
12 \\
15 \\
700+ \\
700+ \\
700+\end{array}$ & $\begin{array}{r}2 \\
25 \\
26 \\
47 \\
64 \\
106 \\
247\end{array}$ & $\begin{array}{r}0 \\
134 \\
154 \\
191 \\
366 \\
403 \\
432\end{array}$ \\
\hline$\overline{\mathbf{X}}$ & 322.7 & $136.1+$ & 31.1 & $306.9+$ & 73.9 & 240.0 \\
\hline
\end{tabular}

apparatus from which the ledge had been retracted and the shock source disconnected for a 10-min RP period. Subjects of no treatment were merely handled at the scheduled time. At the end of $10-\mathrm{min} \mathrm{RP}$, the subject was returned to its home cage where it spent 3 days to allow for drug metabolism.

After 3 days, the subject was returned to the apparatus and put on the extended ledge to begin trials until a criterion of 5 consecutive min on the grid was reached. If the subject failed to reach criterion in 700 trials, testing was terminated and a score of $700+$ was assigned. The contingencies of posttreatment trials were identical to training trials except, of course, shock did not occur, although the sounds of the shock generator did continue as in training.

There were seven subjects in each group except the group of placebo injections which had 11 subjects. During avoidance training, number of trials that resulted in avoidance and duration of footshock were tabulated. After treatments, the number of trials and "avoidances" (climbs to ledge within $10 \mathrm{sec}$ ) to criteria were tabulated. Number of trials and "avoidances" to criteria are highly correlated $($ rho $=.99)$; therefore only trials are presented.

\section{RESULTS}

Kruskal-Wallis analysis of variance (ANOVA) of shock taken during training, with data grouped according to the subjects' eventual treatments, indicated that groups did not differ reliably prior to treatments $(\mathrm{H}=6.5$, df $=$ $5, \mathrm{p}>.20)$. Kruskal-Wallis ANOVA of avoidances did indicate differences among groups prior to treatment $(\mathrm{H}$ $=13.3, \mathrm{df}=5, \mathrm{p}=.02$ ). Subjects of no treatment made the most avoidances $(M=141.7$ out of 149 possibles $)$ while subjects of the $20 \mathrm{mg} / \mathrm{Kg}$ Amytal group made the least $(M=134.8)$. A Spearman rank order correlation, however, indicated only a slight relationship between avoidance scores prior to treatment and posttreatment trials to criterion (rho $=.11$ ). The conclusion drawn from these analyses was that differences among groups prior to treatment did not systematically affect posttreatment outcomes, thereby allowing analyses of the posttreatment measure without taking into account pretreatment differences.

Posttreatment trials to criterion are presented in Table 1. Kruskal-Wallis ANOVA indicates reliable difference among groups $(\mathrm{H}=13.7, \mathrm{df}=5, \mathrm{p}=.02)$. Mann-Whitney Us and associated probabilities derived from comparisons of each group with every other group are presented in Table 2.

Using Ryan's standards of judging reliable differences among multiple comparisons (Kirk, 1968), it can be concluded that the groups of 2 mg-amphetamine, of $10 \mathrm{mg}$-Amytal, and of placebo differed reliably from no treatment. Although subjects of $10 \mathrm{mg}$-amphetamine and $20 \mathrm{mg}$-Amytal received RP, analyses indicate no reliable differences when compared to subjects of no treatment. The only drug group that differed reliably from the subjects of placebo was that of the subjects of 2 mg-amphetamine.

\section{DISCUSSION}

The finding that RP reduces persisting responding replicates a large number of reports (e.g., Baum, 1970) and it has been our finding that brief to moderately long RP periods also increase the variance compared to no treatment subjects or subjects of treatments that are more effective (e.g., range of no treatment group $=374$ and range of placebo-brief RP is greater than 700).

Because of the small number of subjects in each group and because of the conservative statistics used for comparisons among groups, there is a danger of concluding that there are no differences when there are significant differences. Perhaps, for example, further testing would reveal that the high dose of Amytal during RP actually enhanced persisting responding compared to RP by itself.

The data verify the conclusions drawn by Cooper et al. (1974). The relaxing and "tranquilizing" drugs, especially in high doses, are remarkably inefficient adjuncts of RP. Amphetamine

Table 2

Mann-Whitney Us and $p$ Values

\begin{tabular}{|c|c|c|c|c|c|c|}
\hline \multirow[b]{2}{*}{ Groups } & \multirow{2}{*}{$\begin{array}{c}\text { A } \\
\text { No } \\
\text { Treatment } \\
\end{array}$} & \multirow{2}{*}{$\begin{array}{c}\text { B } \\
\text { Placebo } \\
\end{array}$} & $\mathrm{C}$ & $\mathrm{D}$ & $\mathrm{E}$ & $\mathrm{F}$ \\
\hline & & & \multicolumn{2}{|c|}{ Amphetamine } & \multicolumn{2}{|c|}{ Amytal } \\
\hline A & & $\approx .003$ & $<.001$ & $>.10$ & .002 & .130 \\
\hline B & 8 & & $\approx .006$ & $>.10$ & $>.10$ & $>.10$ \\
\hline $\mathrm{C}$ & 0 & 11 & & $>.10$ & $>.10$ & .011 \\
\hline D & 21 & 34 & 20 & & $>.10$ & $>.10$ \\
\hline E & 3 & 31 & 23 & 24 & & .036 \\
\hline $\mathrm{F}$ & 15 & 20 & 6 & 24 & 10 & \\
\hline
\end{tabular}


in low doses is an efficient adjunct. The higher dose of amphetamine produced either little or a great deal of responding. Perhaps, a higher dose of amphetamine would lead to a uniformly high response output.

In general, it appears that any high doses of a psychoactive drug used as an adjunct to RP is likely to produce an increment in persisting avoidance. The state produced by the high doses are likely to be aversive and the result is to produce sensitization of anxiety fear rather than desensitization (Amit \& Baum, 1970). All low doses of psychoactive agents, however, are not efficient adjuncts to RP. The fact that low doses of amphetamine are considerably more effective adjuncts to RP than fear-reducing agents suggests the necessity for fear expression before deconditioning can take place. The "relaxation" and distraction produced by most doses that have been tested as adjuncts to RP does not seem to hasten the deconditioning process. resistance-to-extinction of an avoidance response induced by certain drugs. Psychological Reports, 1970, 27, 310.

Baum, M. Extinction of avoidance responding through response prevention (flooding). Psychological Bulletin, 1970, 74, 276-284.

Cooper, S., Coon, K., Mejta, C., \& Reid, L. Methods of deconditioning persisting avoidance: Amphetamine, chlorpromazine and chlordiazepoxide as adjuncts to response prevention. Physiological Psychology, 1974, 2, 519-522.

Kamano, D. K. Using drugs to modify the effect of response prevention on avoidance extinction. Behavior Research and Therapy, 1972, 10, 367-370.

Kirk, R. E. Experimental design: Procedures for the behavioral sciences. Belmont, California: Brooks/Cole. 1968.

Voss, E. Mejta, C., \& Reid, L. Methods of deconditioning persisting avoidance: response prevention and counterconditioning after extensive training. Bulletin of the Psychonomic Society, $1974,3,345-347$.

\title{
REFERENCES
}

A mit, A., \& Baum, M. Comment on the increased

\section{Conditioned inhibition of the rabbit nictitating membrane response as a function of CS-UCS interval}

\author{
WILLIAM J. MAHONEY, SUZANNE E. KWATERSKI, and JOHN W. MOORE \\ University of Massachusetts, Amherst, Massachusetts
}

\begin{abstract}
Albino rabbits received differential conditioning in either a simple differential conditioning paradigm $(\mathrm{CS}+=$ light; $\mathrm{CS}-=$ tone) or a conditioned inhibition paradigm $(\mathrm{CS}+=$ light; $\mathrm{CS}-=$ light plus tone) at CS-UCS intervals (ISIs) of $.25, .5$, or $1.5 \mathrm{sec}$. Combined-cue summation tests and the results of subsequent conditioning to the tone (retardation tests) indicated that the tone acquired inhibitory properties at the longer ISIs but was "tuned out" at the shortest ISI resulting in a loss of salience.
\end{abstract}

The main purpose of this investigation was to assess the effect of CS-UCS interval on the strength of a Pavlovian conditioned inhibitor using summation and retardation tests of inhibition like those recommended by Rescorla (1969) and previously employed in our laboratory (e.g., Marchant, Mis, \& Moore, 1972; Marchant \& Moore, 1974). The specific hypothesis tested was that increasing a CS-UCS interval over that most efficient for simple conditioning would enhance the strength of the conditioned inhibitor, an expectation based on observations from both human and rabbit eye blink preparations that the CS-UCS interval optimal for differential conditioning is somewhat longer than that optimal for simple conditioning (Chisholm, Hupka, \& Moore, 1969; Hartman \& Grant, 1962; Vandercar \& Scheiderman, 1967).

This research was supported by National Science Foundation Grant GB 24557 to the third author. Requests for reprints should be sent to John W. Moore, Middlesex House, Department of Psychology, University of Massachusetts, Amherst, Massachusetts 01002 . The second author is now at Westfield State College, Westfield, Massachusetts.

\section{METHOD}

\section{Subjects and Apparatus}

The subjects were 48 naive albino rabbits. A detailed description of the apparatus is available elsewhere (e.g., Marchant, Mis, \& Moore, 1972). Briefly, four animals were run concurrently in individually ventilated and soundproofed file drawers while restrained in Plexiglas (Gormezano) boxes. A "minitorque" potentiomenter mounted on the rabbit's head was connected by a small metal hook and thread to a nylon loop sutured into the nictitating membrane (NM) of the right eye. Movement of the right NM produced a dc signal which was amplified and recorded on a Grass 5D oscillograph. A conditioned response (CR) was defined as a pen deflection of $1 \mathrm{~mm}$ (corresponding to an extension of the membrane of less than $1 \mathrm{~mm}$ ) occurring within the CS-UCS interval. The UCS was an ac shock of $2 \mathrm{~mA}$ and $50-\mathrm{msec}$ duration delivered through two stainless steel wound clip (Clay Adams, $9 \mathrm{~mm}$ ) electrodes attached to the skin of the intraorbital region of the right eye. Conditioned stimuli were as follows: (a) $\mathrm{CS}_{1}$ was the onset of two $4.5-\mathrm{V}$ incandescent lights mounted behind two translucent white plastic screens located on either side of the speaker directly in front of the animal; (b) $\mathrm{CS}_{2}$ was a burst of white noise at $80 \mathrm{~dB}$ (SPL); (c) $\mathrm{CS}_{3}$ was a tone of $1200 \mathrm{~Hz}$ at $85 \mathrm{~dB}$ delivered over a speaker located directly in front of the subject. On reinforced trials, the UCS overlapped the final $50 \mathrm{msec}$ of the CS. 